\section{A SIMPLE RESTRAINT.}

CHARLES S. WHITE, M.D.

Associate In Surgery, Emergency Hospital. WASHINGTON, D. .C.

If often becomes necessary to restrain, for a brief period, some patients admitted to the accident ward of a hospital. In the semi-conscious state following the grand mal of epilepsy, in hysterical males particularly, alcoholic delirium, concussion of the brain, cocainism and similar conditions of cerebrospinal excitability or incoordination, temporary measures are demanded until therapeutics or hydrotherapeutics can be rationally employed. The majority of such patients will not remain in bed; moral suasion is useless; and sometimes the patients are perverse, combative, pugnacious, and even homicidal.

In the emergency hospital, at my suggestion, we have had made a hammock of one-fourth inch cotton rope, seven feet six inches long, six feet wide at its center, tanering to three feet at each end. From the ends gny-ropes extend two feet six inches and terminate about an iron ring three inches in diameter. To use the hammock as a restraint, it is spread on a bed, the patient placed on it, and the sides folded over to meet in the middle line above him. The ends and free edges are then laced up by a piece of rope about twelve feet long, passing through the meshes, and securely tied. The patient bccomes enclosed in a torpedo-like rope lattice, fitting him snugly and preventing excessive movements or his escape. The hammock is then suspended from looks fastened in the wall. The bed can be removed or left under him.

The constant use of this simple apparatus for nearly a year has proved its merit. It is comfortable, minimizes the possibility of injury, and it is clean, in that any dejecta escape at once, and the patient is not compelled to lie in them. The patient is rarely kept in the hammock for more than three or four hours. and not uncommonly he is aroused from a peaceful sleep to be discharged. The material for the entire outfit costs less than four dollars, and any one with a nautical turn can knit the hammock. It can be scrubbed and sterilized without injury.

The Farragut.

\section{A SIMPIE DEVICE FOR FACILITATING SPHYGMOMANOMETRY.}

WILLIAM L. BANER, M.D. Visiting Physician, St. Vincent's Hospital. NEW YORK.

The double-bulb sphygmomanometers, such as the Riva Rocci and the Cook, are comparatively easy to use. Unfortunately these instruments are not available for recording diastolic pressure, and the large netted bulb is not at all durable. In fact, it is apt to blow out at the most inopportune moment. In using Janeway's or other single-bulb sphygmomanometer considerable skill is required. The novice, in particular, is apt to give a very jerky performance. It is certainly not at all rare to see two hospital internes taking a blood pressure where one ought to be sufficient, the assistant in each case manipulating the needle-valve while the operator "ontrols the pulse and bulb.

'I'hat this difficulty is a real one is shown by the various suggestions which from time to time have ap- peared in the medical press. The tension indicator of Dr. Louis F. Bishop, of New York, using water pressure, is a sort of crude protest against the difficulties encountered in using the fairly accurate mercury manometer. Dr. W. A. Ruble, ${ }^{1}$ of Washington, suggests that the nebulizer compressed air tank be utilized in place of the bulb. Of course we are not all provided with nebulizer tanks, and such an apparatus is not portable. In addition to this, unless the regulator is very carefully adjusted there is apt to be a shower of mercury.

Since last November I have been using on my Janeway sphygmomanometer a little device which enables the operator to keep one hand on the pulse and one on the bulb from start to finish, and has much simplified the technic and shortened the procedure. This consists in substituting an ordinary atomizer bulb for the Politzer bag, and placing a check-valve between this bulb and the needle-valve. This check-valve is of the type used in pneumatic tires, the spring being somewhat weaker. It can be regulated to a nicety without trouble, and once properly adjusted need not be touched for months. The proper adjustment allows the mercury to sink back very slowly when the bulb is released. If it does not fall at all the valve is too tight. If it falls too rapidly the valve is not tight enough. With the correct adjustment the mercury can be brought with case to any desired point on the scale and hold there indefinitely by slight pressure on the bulb.

The use of this little valve permits the determination of the diastolic pressure. It is much easier to handle than the double bulb, and much more durable. It has been in continuous use for several months now on my service at St. Vincent's Hospital and has given much satisfaction to the internes.

'I'hey can be made by any one, the only difficult point being the proper adjustment of the spring and plunger, cach individual valve being tested on the sphygmomanometer and brought to the proper tension.

40 West Sixty-eighth Street.

\section{THE RELATION BETWEEN WEIGHT AND AGE IN THE FETUS.}

LUCIUS TUTTLE, M.D. PHILADELPHIA.

The relationship between the length of the fetus and its age is easily kept in mind with the aid of Haase's rule, viz., during the first five months of gestation the age in months is multiplied by itself, and during the latter half of gestation the age is multiplied by five, the resulting figure being the length of the fetus in centimeters. I have endeavored to formulate a rule which shall furnish an equally easy method for recalling the weight of the fetus at any given age.

According to Roberts, ${ }^{2}$ the slower growth of the fetal head during the later months of pregnancy is compensated for by the more rapid growth of the limbs; and the formation of dense bony tissue is counterbalanced by the formation of light fatty tissue, the result being that the specific gravity of the fetus is not materially altered, and its volume, and therefore its mass also, are proportional to the cube of any linear dimension, or to the cube of its age. Accordingly, he takes the cube of

1. The Jodrnat A. M. A., June 6, 1908.

2. Lancet, Feb. 3, 1906, p. 295. 